\title{
Non-linear Control of UPFC for the Stabilization of Synchronous Generator
}

\author{
M.Jagadeesh Kumar ${ }^{1}$ Dr.S.S.Dash ${ }^{2}$ M.Arun Bhaskar ${ }^{3}$ C.Subramani ${ }^{4}$ \\ A.S.Pilot Immanuvel ${ }^{5}$ R.Prasanna ${ }^{6}$ \\ 1,3,6-Dept. Of EEE, Velammal Engineering College,Chennai-66 \\ 2,4,5-Dept. Of EEE, SRM University Kattankulathur-03
}

\begin{abstract}
An Unified Power Flow Controller (UPFC) is a typical Flexible AC Transmission System (FACTS) device playing a vital role as a stability aid for large transient disturbances in an interconnected power system. This paper deals with the design of Feedback Linearising Controller (FBLC) for UPFC.The disturbances are created in the SMIB system and the results are simulated. The results proved the supremacy of the Power System Stabilizer (PSS) equipped with FBLC over the PSS equipped with Proportional Integral(PI) controller.
\end{abstract}

\section{Keywords}

UPFC, FACTS, FBLC, PSS, PI.

\section{INTRODUCTION}

\subsection{Transient Stability}

Transient stability refers to "the ability of a power system to maintain synchronism when subjected to a severe transient disturbance" [1]. Stabilization of a synchronous generator is undoubtedly one of the most important problems in power system control. Power system stabilizers (PSS) and Automatic voltage regulators (AVR) with exciter are normally employed to damp out the electromechanical oscillations as well as for the postfault busvoltage recovery. However, it is well knownthat the performances of PSS and AVR are limited since their designs are primarily based on linear control algorithms. In the event of large faults, the nonlinearities of the system become very severe, thereby putting limitations on the performances of classical control designs. Thus, the most appropriate approach for controller design for a power system is the use of nonlinear control theory, i.e., multivariable feedback linearization scheme. The application of feedback linearization approaches for power system control was first investigated by Marino [2] and subsequently by several researchers [3-5]. This control technique has also been successfully applied to control of drives and power electronics based systems [6-8]. Successful applications of FACTS equipment for power flow control, voltage control and transient stability improvement have been reported in the literature [913].The rapid development of power electronics technology provides opportunities to develop new power equipment to improve the performance of the actual power systems. During the last decade, a technology called "Flexible AC Transmission Systems" (FACTS) have been proposed and implemented.

\subsection{UPFC}

The new generation and most dominant converters needed in FACTS controllers such as Static Synchronous Compensator (STATCOM), Static Synchronous Series Compensator (SSSC) and by the combination of both the Unified Power Flow Controller (UPFC) are based on the voltage-source inverters (VSI). The use of VSI has been widely accepted as the next generation of reactive power controllers of power system to replace the conventional VAR compensation, such as the TSC and TCR. The major applications are: voltage stability enhancement, damping torsional oscillations, power system voltage control, and power system stability. These applications can be implemented with a suitable control as noticed in [14-16]. The UPFC is implemented practically by using two similar solid-state phase voltage source converters (shunt compensation block and series compensation block) that are connected to a common DC link capacitor. Each converter is coupled with a transformer, as shown in Fig 1.

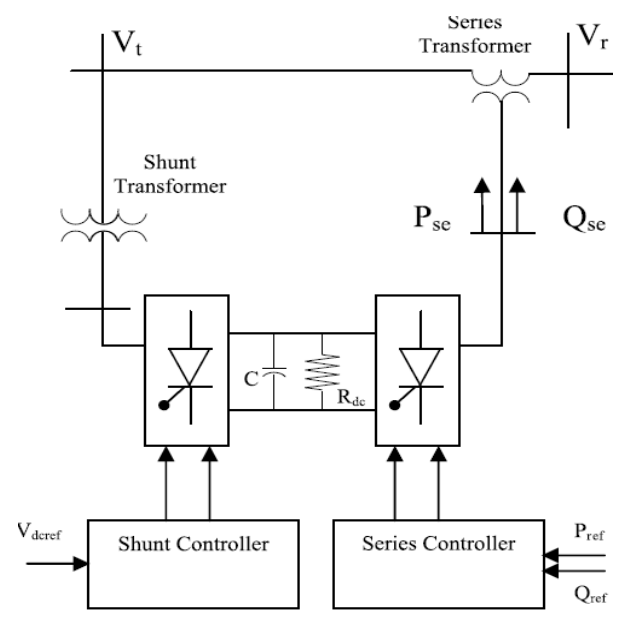

Fig 1.Power System with an UPFC

\section{MODELING OF UPFC}

\subsection{UPFC installed in SMIB system}

The mathematical model of the UPFC is derived here in the $d-q$ (synchronously rotating at the system angular frequency $\omega$ ) frame of reference. This is followed by a detailed description of theconventional PI control strategy employed for active and reactive power control using UPFC.The equivalent circuit model of a power system equipped with a UPFC is shown in Fig 2. The 
series and shunt VSIs are represented by controllable voltage sources $V_{c}$ and $V_{p}$, respectively. $R_{p}$ and $L_{p}$ represent the resistance and leakage reactance of the shunt transformer respectively. Leakage reactance and resistance of series transformer have been neglected.

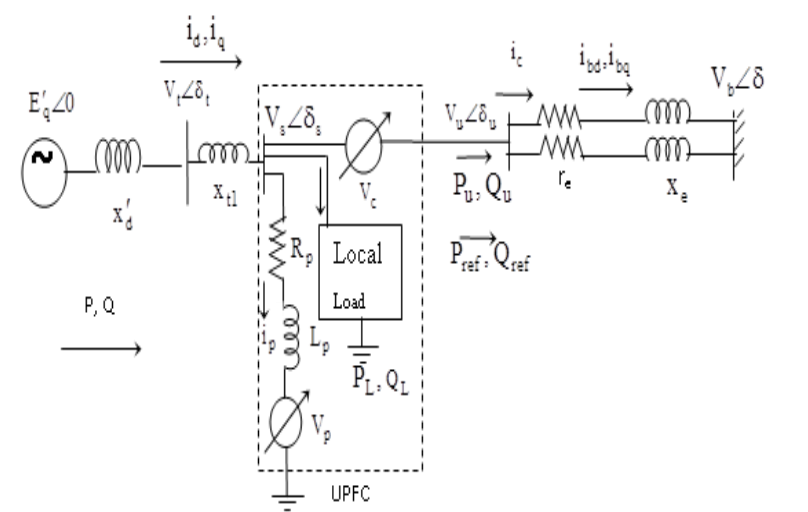

Fig 2.Single line diagram of UPFC installed in power system

\subsection{Synchronous Generator}

The synchronous generator is described by a third-order nonlinear mathematical model.

$\frac{d \delta}{d t}=\Delta \omega(1)$

$$
\begin{aligned}
& \frac{d \Delta \omega}{d t}=\frac{1}{M}\left[P_{m}-E_{q^{\prime}} i_{q}-\left(x_{q}-x_{d \prime}\right) i_{d} i_{q}\right] \\
& \frac{d E_{q^{\prime}}}{d t}=\frac{1}{T_{d o^{\prime}}}\left[E_{f d}-E_{q^{\prime}}-\left(x_{d}-x_{d \prime}\right) i_{d}\right](3)
\end{aligned}
$$

Where

$$
\begin{aligned}
& \Delta \delta=\delta-\delta_{o} \\
& \Delta \omega=\omega-\omega_{o} \\
& \text { Subscript 'o' indicates the initial values. }
\end{aligned}
$$

\subsection{AVR and PSS}

The excitation system of the generator consists of a simple Automatic Voltage regulator (AVR) along with a supplementary Power System Stabiliser (PSS). The complete AVR and PSS control system is shown in Fig 3.

The mathematical equations are given below,

$$
\begin{aligned}
\frac{d \Delta E_{f d}}{d t} & =\left[\frac{K_{e}\left(V_{t}^{r e f}-V_{t}+u_{p s s}\right)}{T_{e}}-\frac{\Delta E_{f d}}{T_{e}}\right] \\
\frac{d u_{p s s}}{d t} & =\left(K_{p w} \frac{d \Delta \omega}{d t}+K_{i w} \Delta \omega\right)
\end{aligned}
$$

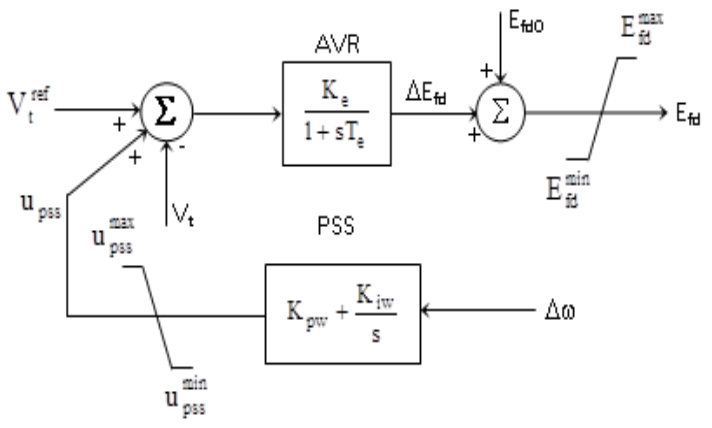

\section{Fig 3.Exciter and PSS control system}

\subsection{Modeling of Shunt Converter}

$$
\begin{aligned}
{\left[R_{p}+L_{p} \frac{d}{d t}\right] i_{p}=} & V_{s}-V_{p} \\
\frac{d i_{p}}{d t} & =-R_{p} \frac{i_{p}}{L_{p}}+\frac{1}{L_{p}}\left(V_{s}-V_{p}\right)
\end{aligned}
$$

Where:

$$
\begin{gathered}
\mathrm{i}_{\mathrm{p}}=\left[\mathrm{i}_{\mathrm{pa}} \mathrm{i}_{\mathrm{pb}} \mathrm{i}_{\mathrm{pc}}\right]^{\mathrm{T}} \\
\mathrm{V}_{\mathrm{s}}=\left[\mathrm{V}_{\mathrm{sa}} \mathrm{V}_{\mathrm{sb}} \mathrm{V}_{\mathrm{sc}}\right]^{\mathrm{T}} \\
R_{p}=\left[\begin{array}{ccc}
R_{p} & 0 & 0 \\
0 & R_{p} & 0 \\
0 & 0 & R_{p}
\end{array}\right] \text { and } L_{p}=\left[\begin{array}{ccc}
\left.\mathrm{V}_{\mathrm{pa}} \mathrm{V}_{\mathrm{pb}} \mathrm{V}_{\mathrm{pc}}\right]^{\mathrm{T}} & 0 & 0 \\
0 & L_{p} & 0 \\
0 & 0 & L_{p}
\end{array}\right]
\end{gathered}
$$

Under the assumption that the system has no zero sequence components, all currents and voltages can be uniquely represented by equivalent space phasors and then transformed into the synchronous $d-q-o$ frame by applying the following transformation ( $\mathrm{q}$ is the angle between the $d$-axis and reference phase axis):

$$
T=\sqrt{\frac{2}{3}}\left[\begin{array}{ccc}
\cos \theta & \cos \left[\theta-\frac{2 \pi}{3}\right] & \cos \left[\theta+\frac{2 \pi}{3}\right] \\
-\sin \theta & -\sin \left[\theta-\frac{2 \pi}{3}\right] & -\sin \left[\theta+\frac{2 \pi}{3}\right] \\
\frac{1}{\sqrt{2}} & \frac{1}{\sqrt{2}} & \frac{1}{\sqrt{2}}
\end{array}\right]
$$

given by,

Thus, the transformed dynamic equations are

$$
\begin{gathered}
\frac{\mathrm{di}_{\mathrm{pd}}}{\mathrm{dt}}=-\mathrm{R}_{\mathrm{p}} \frac{\mathrm{i}_{\mathrm{pd}}}{\mathrm{L}_{\mathrm{p}}}+\frac{1}{\mathrm{~L}_{\mathrm{p}}}\left(\mathrm{V}_{\mathrm{sd}}-\mathrm{V}_{\mathrm{pd}}\right)+\omega \mathrm{i}_{\mathrm{pq}}(8) \\
\frac{\mathrm{di}_{\mathrm{pq}}}{\mathrm{dt}}=-\mathrm{R}_{\mathrm{p}} \frac{\mathrm{i}_{\mathrm{pq}}}{\mathrm{L}_{\mathrm{p}}}+\frac{1}{\mathrm{~L}_{\mathrm{p}}}\left(\mathrm{V}_{\mathrm{sq}}-\mathrm{V}_{\mathrm{pq}}\right)-\omega \mathrm{i}_{\mathrm{pd}}(9)
\end{gathered}
$$

bus voltage.

Where $\omega$ is the angular frequency of the $\mathrm{AC}$

\subsubsection{Cascade Control Strategy of Shunt Converter}

The conventional control strategy for this inverter concerns with the control of ac-bus and dc-link voltage. The dual control objectives are met by generating appropriate current reference and, then, by regulating those currents. PI controllers are conventionally employed for both the tasks while attempting to decouple the d-and q- axiscurrent regulators. In this study, the strategy adopted in[17] for shunt current control has been taken.The inverter current $\left(i_{p}\right)$ is split into real (in phase with acbus voltage) and reactive components. The reference value for the real current is decided so that the capacitor voltage is regulated by power balance. The reference for reactive component is determined by ac-bus voltage regulator. As per the strategy, the original currents in $\mathrm{d}-\mathrm{q}$ frame $\left(\mathrm{i}_{\mathrm{pd}}, \mathrm{i}_{\mathrm{pq}}\right)$ are now transformed into another frame, $\mathrm{d}^{\prime}-\mathrm{q}$ ' frame, where $\mathrm{d}^{\prime}$-axis coincides with the ac-bus voltage $\left(\mathrm{V}_{\mathrm{s}}\right)$, as shown in Fig 4 . 


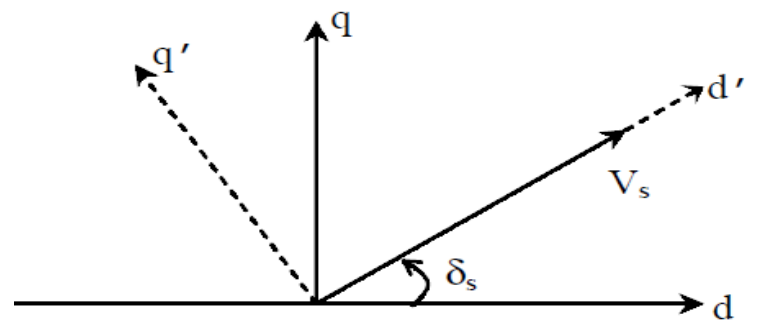

Fig 4.Phasor diagram showing d-q and d'-q' frame

Thus, in (d'-q') frame, the currentsi $i_{p d}$, andi $\mathrm{pq}_{\mathrm{pq}}$, represent the real and reactive currents and they are given by:

$$
\begin{aligned}
& i_{p d^{\prime}}=i_{p d} \cos \delta_{s}+i_{p q} \sin \delta_{s} \quad(10) \\
& i_{p q^{\prime}}=i_{p q} \cos \delta_{s}-i_{p d} \sin \delta_{s}(11)
\end{aligned}
$$

Now, for current control, the same procedure as outlined in [17] has been adopted by re-expressing the above differential equations as:

$$
\begin{array}{r}
\frac{\mathrm{di}_{\mathrm{pd}^{\prime}}}{\mathrm{dt}}=-\mathrm{R}_{\mathrm{p}} \frac{\mathrm{i}_{\mathrm{pd} \prime}}{\mathrm{L}_{\mathrm{p}}}+\frac{1}{\mathrm{~L}_{\mathrm{p}}}\left(\mathrm{V}_{\mathrm{sd}}-\mathrm{V}_{\mathrm{pd} \prime}\right)+\omega \mathrm{i}_{\mathrm{pq}}(12) \\
\frac{\mathrm{di}_{\mathrm{pq}}}{\mathrm{dt}}=-\mathrm{R}_{\mathrm{p}} \frac{\mathrm{i}_{\mathrm{pq}}}{\mathrm{L}_{\mathrm{p}}}+\frac{1}{\mathrm{~L}_{\mathrm{p}}}\left(-\mathrm{V}_{\mathrm{pq}}\right)-\omega \mathrm{i}_{\mathrm{pd}},
\end{array}
$$

Where

$$
\begin{gathered}
V_{p d^{\prime}}=V_{p d} \cos \delta_{s}+V_{p q} \sin \delta_{s} \\
V_{p q^{\prime}}=V_{p q} \cos \delta_{s}-V_{p d} \sin \delta_{s} \\
\omega_{0}=\omega+\frac{\mathrm{d} \delta_{\mathrm{s}}}{\mathrm{dt}}
\end{gathered}
$$

The VSI controlled voltages are as follows:

$$
\begin{aligned}
& \mathrm{V}_{\mathbf{p q}^{\prime}}=-\left(\omega \mathrm{L}_{\mathrm{p}} \mathrm{i}_{\mathbf{p d}^{\prime}}+\mathrm{L}_{\mathrm{p}} \mathrm{u}_{\mathrm{q}^{\prime}}\right) \\
& \mathrm{V}_{\mathrm{pd}{ }^{\prime}}=\omega \mathrm{L}_{\mathrm{p}} \mathrm{i}_{\mathbf{p q}}+\mathrm{V}_{\mathrm{s}}-\mathrm{L}_{\mathrm{p}} \mathrm{u}_{\mathrm{d} \prime}
\end{aligned}
$$

By putting the above expressions for $\mathrm{V}_{\mathrm{pd}}$, and $\mathrm{V}_{\mathrm{pq}}$, in equations (12) and (13) the following set of decoupled equations are obtained.

$$
\begin{aligned}
& \frac{\mathrm{di}_{\mathrm{pd} \prime}}{\mathrm{dt}}=-\frac{\mathrm{R}_{\mathrm{p}}}{\mathrm{L}_{\mathrm{p}}} \mathrm{i}_{\mathrm{pd}^{\prime}}+\mathrm{u}_{\mathrm{d} \prime} \\
& \frac{\mathrm{di}_{\mathrm{pq}}}{\mathrm{dt}}=-\frac{\mathrm{R}_{\mathrm{p}}}{\mathrm{L}_{\mathrm{p}}} \mathrm{i}_{\mathrm{pq}^{\prime}}+\mathrm{u}_{\mathrm{q}^{\prime}}
\end{aligned}
$$

Conventionally, the control signals $\mathrm{u}_{\mathrm{d}}$, and $\mathrm{u}_{\mathrm{q}}$, are determined by linear PI controllers. The complete cascade control architecture is shown below in Fig 5 , where $\mathrm{K}_{\mathrm{p}}, \mathrm{K}_{\mathrm{it}}, \mathrm{K}_{\mathrm{pc}}, \mathrm{K}_{\mathrm{ic}}, \mathrm{K}_{\mathrm{pq}}, \mathrm{K}_{\mathrm{iq}}, \mathrm{K}_{\mathrm{pd}}$ ' and $\mathrm{K}_{\mathrm{id}}$ ' are the respective gains of the PI controllers.

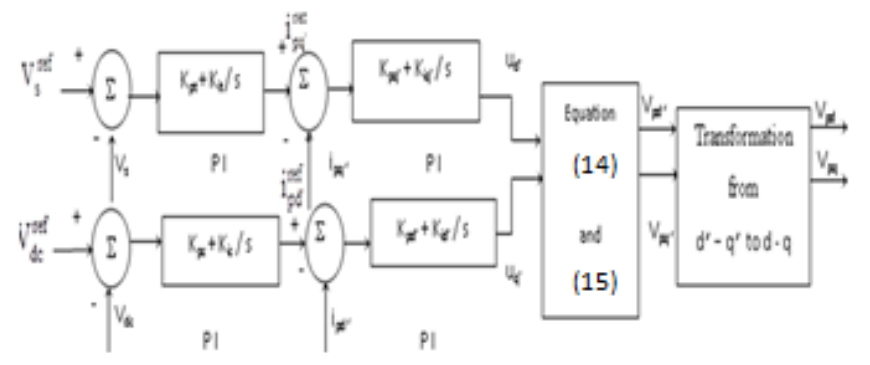

Fig 5. PI-Control Structure of Shunt Converter

\subsection{Modeling of Series Converter}

$$
\begin{aligned}
& \frac{d i_{b d}}{d t}=-\frac{\omega_{b} r_{e}}{x_{e}} i_{b d}+\omega i_{b q}+\frac{\omega_{b}}{x_{e}}\left(V_{u d}-V_{b} \sin \delta\right)(18) \\
& \frac{d i_{b q}}{d t}=-\frac{\omega_{b} r_{e}}{x_{e}} i_{b q}-\omega i_{b d}+\frac{\omega_{b}}{x_{e}}\left(V_{u q}-V_{b} \cos \delta\right)
\end{aligned}
$$

For fast voltage control, the net input power should instantaneously meet the charging rate of the capacitor energy. Thus, by power balance,

$$
\begin{gathered}
P_{s}-P_{u}=V_{s d}\left(i_{p d}+i_{b d}\right)+V_{s q}\left(i_{p q}+i_{b q}\right)-\left(V_{u d} i_{b d}+V_{u q} i_{b q}\right) \\
=V_{d c} i_{d c} \\
=V_{d c}\left(C \frac{d V_{d c}}{d t}+g V_{d c}\right) \\
\frac{d V_{d c}}{d t}=-\frac{g \omega V_{d c}}{b}+\frac{1}{C V_{d c}}\left[V_{s d} i_{p d}+V_{s q} i_{p q}+\left(V_{s d}-V_{u d}\right) i_{b d}+\right. \\
\left.\left(V_{s q}-V_{u q}\right) i_{b q}\right]
\end{gathered}
$$

An appropriate series voltage (both magnitude and phase) should be injected for obtaining the commanded active and reactive power flow in the transmission line, i.e., $\left(\mathrm{Pu}, \mathrm{Q}_{\mathrm{u}}\right)$ in this control. The current references are computed from the desired power references and are given by,

$$
\begin{aligned}
& i_{c d}^{r e f}=\frac{P_{r e f} V_{u d}-Q_{r e f} V_{u q}}{V_{u}^{2}} \\
& i_{c q}^{r e f}=\frac{P_{r e f} V_{u q}-Q_{r e f} V_{u d}}{V_{u}^{2}}
\end{aligned}
$$

The corresponding control system diagram is shown in Fig 6 .

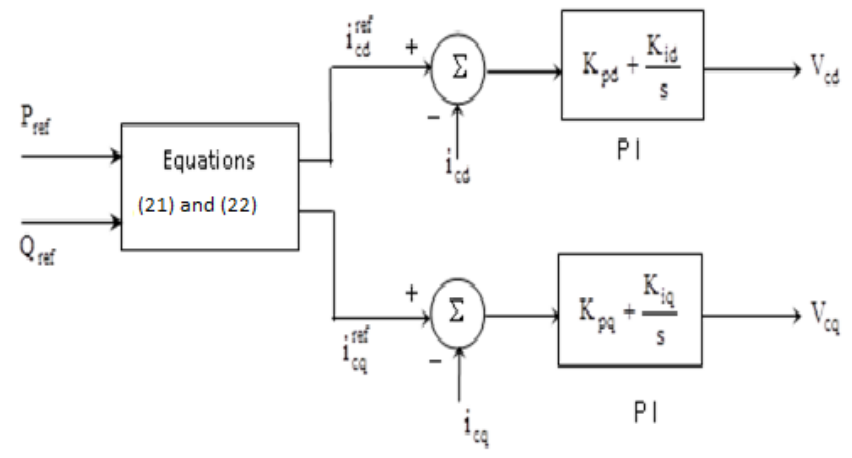

Fig 6. PI-Control of Series Converter

\section{FBLC FOR UPFC}

In this section, the design steps for the feedback linearizing control of UPFC have been presented. In the UPFC control, there are two objectives, i.e. ac bus voltage ( $\mathrm{Vdc}$ ) control. in the following control design, the dynamic equation for Vs is obtained as follows with reference to single line diagram. Now, for the control design, the complete state space model is expressed in the form of equations as follows: 


$$
\left[\begin{array}{l}
x_{1} \\
x_{2} \\
x_{3} \\
x_{4} \\
x_{5} \\
x_{6}
\end{array}\right]=\left[\begin{array}{c}
i_{p d}^{\prime} \\
i_{p q}^{\prime} \\
i_{b d}^{\prime} \\
i_{b q}^{\prime} \\
v_{d c} \\
v_{s}
\end{array}\right]
$$

$$
\left[\begin{array}{l}
u_{1} \\
u_{2} \\
u_{3} \\
u_{4}
\end{array}\right]=\left[\begin{array}{l}
v_{p d}^{\prime} \\
v_{p q}^{\prime} \\
v_{c d}^{\prime} \\
v_{c q}^{\prime}
\end{array}\right]
$$

$$
\begin{aligned}
& x_{1}=i_{p d}^{\prime} \\
& x_{2}=i_{p q}^{\prime} \\
& x_{3}=i_{b d}^{\prime} \\
& x_{4}=i_{b q}^{\prime} \\
& x_{5}=v_{d c}
\end{aligned}
$$

$\dot{x}_{1}=f_{1}(x)+g_{1} u_{1}$

$\dot{x}_{2}=f_{2}(x)+g_{2} u_{2}$

$\dot{x}_{3}=f_{3}(x)+g_{3} u_{3}$

$\dot{x}_{4}=f_{4}(x)+g_{4} u_{4}$

$$
\dot{x}_{5}=f_{5}(x)
$$

Where:

$$
\dot{x}_{6}=f_{6}(x)+g_{61} u_{61}+g_{62} u_{62}+g_{63} u_{63}+g_{64} u_{64}(x)
$$

$$
\begin{aligned}
& f 1(x)=-\left(\frac{R p}{L p}\right) x_{1}+\omega x_{2}+\left(\frac{1}{L p}\right)(V s d) \\
& f 2(x)=-\left(\frac{R p}{L p}\right) x_{2}-\omega x_{1}+\left(\frac{1}{L p}\right)(\mathrm{Vsq}) \\
& f 3(x)=-\left(\frac{R p}{L p}\right) x_{3}+\omega x_{4}+\left(\frac{1}{L e}\right)(\mathrm{Vsd}-\mathrm{Vbd}) \\
& \left.f 4(x)=-\left(\frac{R p}{L p}\right) x_{4}+\omega x_{3}+\left(\frac{1}{L e}\right)\right)(V s q-V b q) \\
& g_{3}=\frac{1}{L_{e}}=g_{4} \\
& f 5(x)=C 1+C 2 \\
& f 51(x)=\left(\frac{1}{\mathrm{C} x_{5}}\right)\left[\operatorname{Vsd} x_{1}+\operatorname{Vsq} x_{2}+(\mathrm{Vsd}-\mathrm{Vud}) x_{3}+(\mathrm{Vsq}\right. \\
& \left.\left.-\operatorname{Vuq}) x_{4}\right)\right] \\
& C 1=\left(\frac{1}{\mathrm{C} x_{5}}\right)[\mathrm{Vsd} f 1+\mathrm{Vsq} f 2+(-\mathrm{Vud}+\mathrm{Vsd}) f 3 \mathrm{f} 3+(-\mathrm{Vuq} \\
& +\mathrm{Vsq}) f 4)+\left(x_{1} \mathrm{dVsd}+x_{2} \mathrm{dVsq}\right. \\
& \left.+x_{3}(\mathrm{dVsd}-\mathrm{dVud})+x_{4}(\mathrm{dVsq}-\mathrm{dVuq})\right] \\
& \mathrm{C} 2=f 51\left[( 1 / \mathrm { C } ( x _ { 5 } { } ^ { 2 } ) ) \left[\left(-\left(\mathrm{Vsd} x_{1}+\mathrm{Vsq} x_{2}+(\mathrm{Vsd}-\mathrm{Vud}) x_{3}\right.\right.\right.\right. \\
& \left.\left.+(\mathrm{Vsq}-\mathrm{Vuq}) x_{4}\right)\right] \\
& \begin{array}{l}
g_{51}=\frac{1}{\mathrm{C} x_{5}}(\text { Vsd g1 }) \\
g_{52}=\frac{1}{\mathrm{C} x_{5}}(\text { Vsq g2 })
\end{array}
\end{aligned}
$$

$$
\begin{aligned}
& g_{53}=\frac{1}{\mathrm{C} x_{5}}(- \text { Vud }+ \text { Vsd }) g 3 \\
& g_{54}=\frac{1}{\mathrm{C} x_{5}}(-\mathrm{Vuq}+\mathrm{Vsq}) \mathrm{g} 4 \\
& f 6(x)=\left(\frac{V s d}{V s}\right)(\operatorname{dvtd}-\operatorname{Re} \mathrm{f} 1+x t 1 \mathrm{f} 2-\operatorname{Re} \mathrm{f} 3+\mathrm{xt} 1 \mathrm{f} 4) \\
& \begin{array}{l}
-\left(\frac{V s q}{V s}\right)(d V t q+\operatorname{Re} * f 2+x t 1 f 1+x t 1 f 3 \\
+ \text { Re f } 4)
\end{array} \\
& g_{61}=-\frac{1}{V s}(\text { Vsd Re g1 }+ \text { Vsq xt1 g1) } \\
& g_{62}=\frac{1}{V s}(V s d x t 1 g 2-\text { Vsq Re g2) } \\
& g_{63}=-\frac{1}{V s}(\text { Vsd Re g3 + Vsq xt1 g3 }) \\
& g_{64}=\frac{1}{V s}(V s d x t 1 \text { g4 - Vsq Re g4) }
\end{aligned}
$$

The outputs of the system are $V s$ and $V d c$.thus,

$$
\begin{gathered}
y_{1=} i_{d s e} \\
y_{2=} i_{q s e} \\
y_{3}=v_{s} \\
y_{4=} v_{d c}
\end{gathered}
$$

By control law, the outputs of the system is given by,

$$
\begin{gathered}
{\left[\begin{array}{l}
\dot{y}_{1} \\
\dot{y}_{2} \\
\ddot{y}_{3} \\
\dot{y}_{4}
\end{array}\right]=\left[\begin{array}{l}
f 3(x) \\
f 4(x) \\
f 6(x) \\
f 5(x)
\end{array}\right]+\left[\begin{array}{cccc}
0 & 0 & g_{3} & 0 \\
0 & 0 & 0 & g_{4} \\
g_{61} g_{62} & g_{63} g_{64} \\
g_{51} g_{52} g_{53} g_{54}
\end{array}\right]\left[\begin{array}{l}
u_{1} \\
u_{2} \\
u_{3} \\
u_{4}
\end{array}\right]} \\
=A(x)+E(x)\left[\begin{array}{l}
u_{1} \\
u_{2} \\
u_{3} \\
u_{4}
\end{array}\right]
\end{gathered}
$$

Where:

$$
\left[\begin{array}{l}
u_{1} \\
u_{2} \\
u_{3} \\
u_{4}
\end{array}\right]=\left(E^{-1(x)}\left[-A(x)+\left[\begin{array}{l}
v_{1} \\
v_{2} \\
v_{3} \\
v_{4}
\end{array}\right]\right]\right)
$$

The non-singularity of $\boldsymbol{E}(\boldsymbol{x})$ can be observed by computing the determinant of $\boldsymbol{E}(\boldsymbol{x})$.

$\boldsymbol{E}(\boldsymbol{x})$ is non-singular in the operating ranges of $V s$ and $V d c$. For tracking of $V s$ and $V d c$, the new control inputs $v 1, v 2, v 3$ and $v 4$ are selected as (by both proportional and integral control):

$$
\left(\begin{array}{c}
V_{1} \\
V_{2} \\
V_{3} \\
V_{4}
\end{array}\right)=\left(\begin{array}{c}
\dot{y}_{1 r e f}+K_{11} e_{1}+K_{12} \int e_{1} d t \\
\dot{y}_{2 r e f}+K_{11} e_{2}+K_{12} \int e_{2} d t \\
\ddot{y}_{3 r e f}+K_{11} e_{3}+K_{12} \int e_{3} d t \\
\dot{y}_{4 r e f}+K_{21} \dot{e}_{4}+K_{22} e_{4}+K_{23} \int e_{4} d t
\end{array}\right)
$$

Where:

$$
e_{1}=i_{d s e}^{r e f}-i_{d s e}
$$




$$
\begin{gathered}
e_{2}=i_{q s e}^{r e f}-i_{q s e} \\
e_{3}=V_{s}^{r e f}-v_{s} \\
e_{4}=v_{d C}^{r e f}-v_{d C}
\end{gathered}
$$

The gain parameters $K_{11}, K_{12}, K_{21}, K_{22}, K_{23}$ are determined by assigning desired poles on the left half $s$-plane and, thus, asymptotic tracking control to the reference can be achieved.

\section{SIMULATION RESULTS}

\subsection{CASE-I}

The synchronous generator is assumed to operate atP $=1.2 \mathrm{p}$.u.and $\mathrm{Q}=0.85$ p.u. A sudden increase of $20 \%$ in governor input is introduced to occur for the duration of 100 msThis sudden increase in governor input is created at $500 \mathrm{~ms}$ and removed at $600 \mathrm{~ms}$.
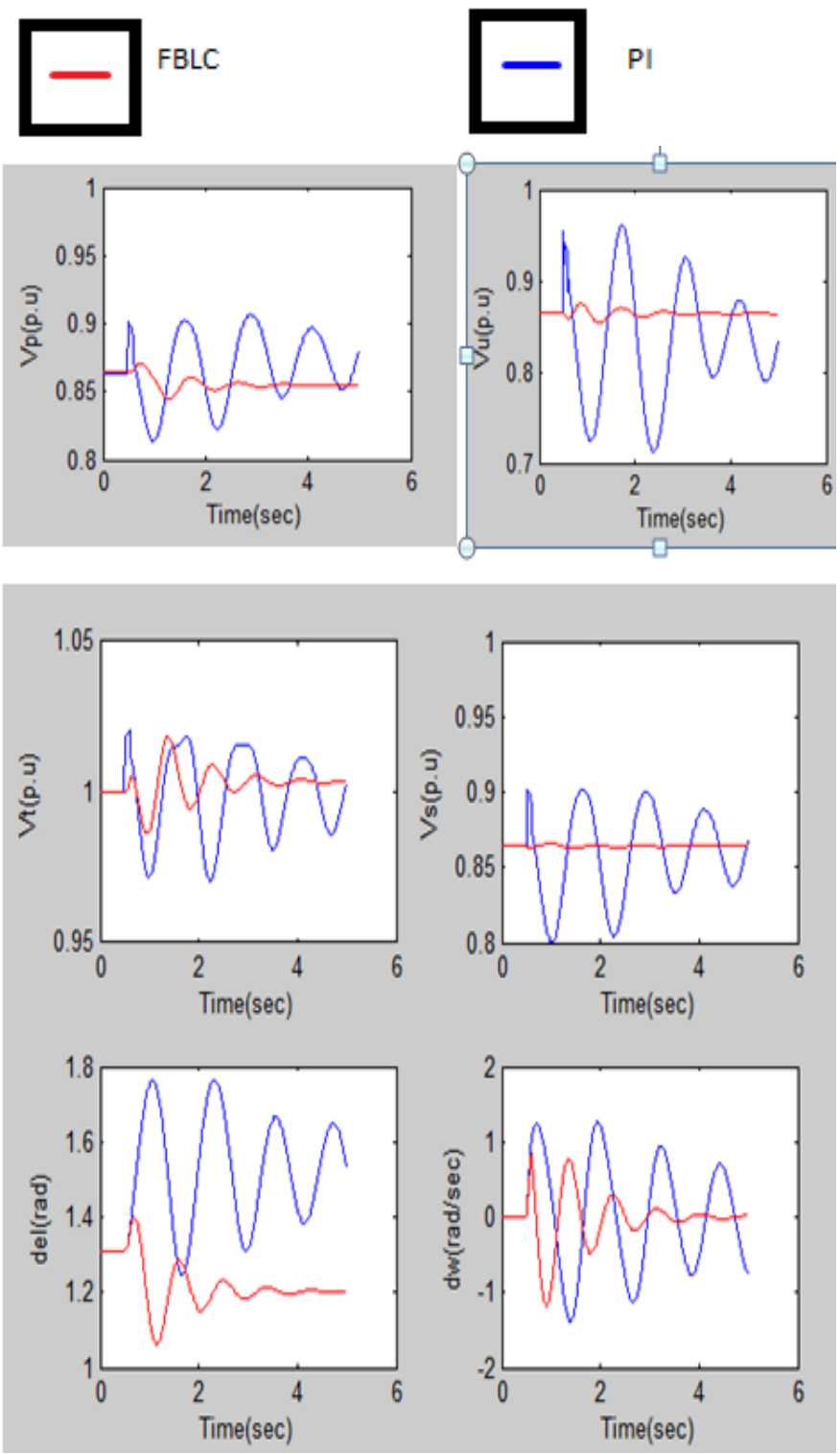

Fig 7.Comparison of transient responses between FBLC and PI-Controller

\subsection{CASE-II}

The synchronous generator is assumed to operate at $\mathrm{P}=1.2 \mathrm{p}$.u.and $\mathrm{Q}=0.5$ p.u. A sudden increase of $20 \%$ in governor input is introduced to occur for the duration of 100 msThis sudden increase in governor input is created at $500 \mathrm{~ms}$ and removed at $600 \mathrm{~ms}$.
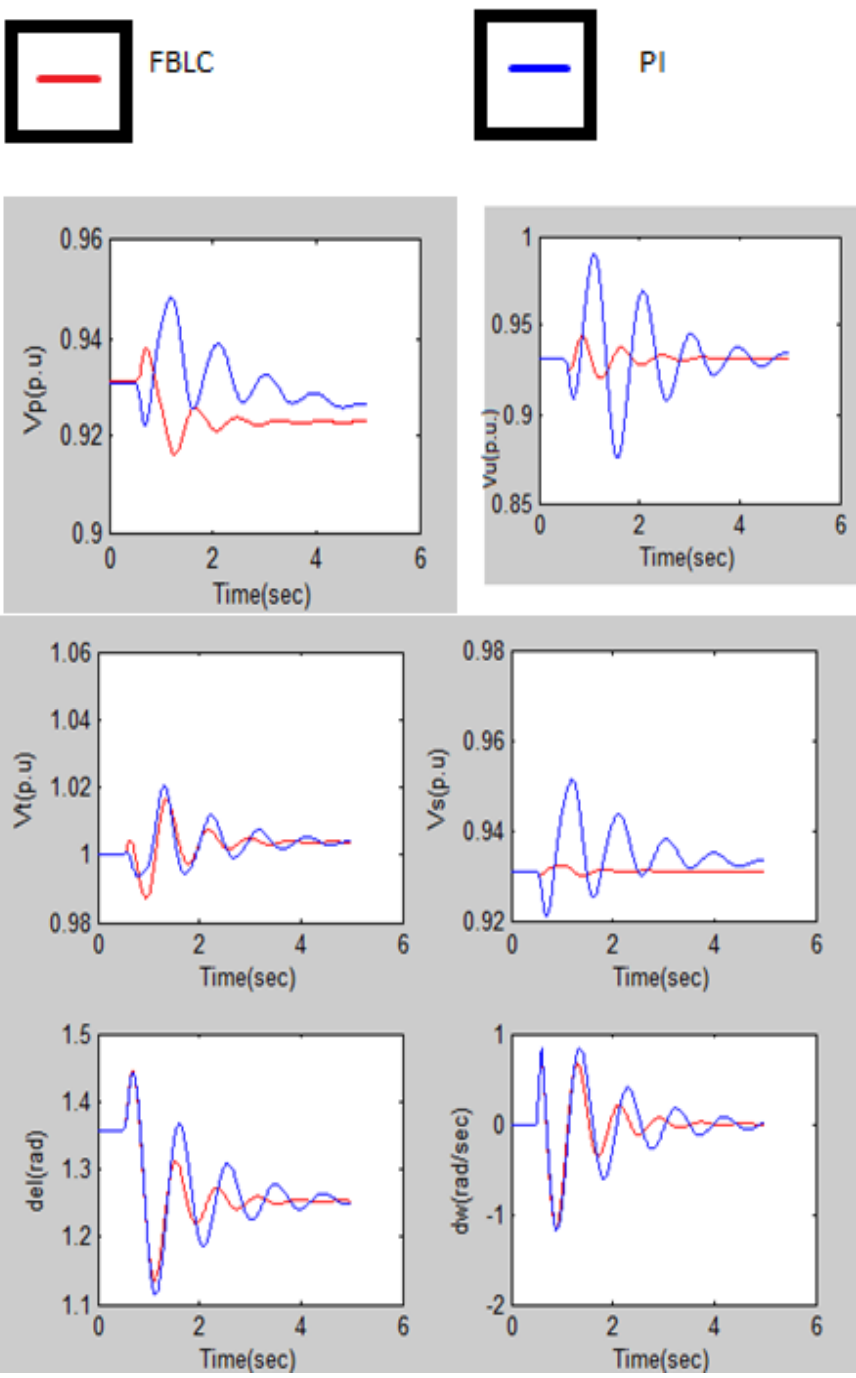

Fig 8.Comparison of transient responses between FBLC and PI-Controller

\section{NOMENCLATURE}

\begin{tabular}{|c|l|}
\hline Symbols & \multicolumn{1}{c|}{ Description } \\
\hline$\delta$ & rotor angular velocity of synchronous machine \\
\hline$\omega$ & rotor angle of synchronous machine \\
\hline $\mathrm{P}_{\mathrm{m}}$ & input mechanical power \\
\hline $\mathrm{M}$ & moment of inertia \\
\hline
\end{tabular}




\begin{tabular}{|c|c|}
\hline $\mathrm{E}_{\mathrm{q}}$ & Voltage proportional to main field flux linkage \\
\hline$i_{d}$ & direct axis current \\
\hline $\mathrm{i}_{\mathrm{q}}$ & quadrature axis current \\
\hline $\mathrm{x}_{\mathrm{d}}$ & direct axis synchronous reactance \\
\hline $\mathrm{x}_{\mathrm{d}}$ & direct axis transient reactance \\
\hline $\mathrm{T}_{\mathrm{do}}$ & direct axis open circuit time constant \\
\hline $\mathrm{E}_{\mathrm{fd}}$ & $\begin{array}{l}\text { Equivalent stator emf corresponding to field } \\
\text { voltage, }\end{array}$ \\
\hline & $\mathrm{E}_{\mathrm{fd}}^{\max } \leq \mathrm{E}_{\mathrm{fd}} \geq \mathrm{E}_{\mathrm{fd}}^{\min }$ \\
\hline$\Delta \omega$ & speed deviation of the machine \\
\hline $\mathrm{K}_{\mathrm{e}}$ & gain of amplifier of excitation system \\
\hline $\mathrm{V}_{\mathrm{t}}$ & terminal voltage of synchronous machine \\
\hline $\mathrm{u}_{\mathrm{pss}}$ & PSS output signal $\quad \mathrm{u}_{\mathrm{pss}}^{\max } \leq \mathrm{u}_{\mathrm{pss}} \geq \mathrm{u}_{\mathrm{pss}}^{\min }$ \\
\hline $\mathrm{T}_{\mathrm{e}}$ & Electromagnetic torque of generator \\
\hline $\mathrm{V}_{\mathrm{t}}^{\mathrm{ref}}$ & Reference terminal voltage \\
\hline $\mathrm{K}_{\mathrm{iw}}$ & Integral gain constant of PSS \\
\hline $\mathrm{K}_{\mathrm{pw}}$ & Proportional gain constant of PSS \\
\hline $\mathrm{E}_{\mathrm{fd} 0}$ & Steady state value of field voltage \\
\hline $\mathrm{R}_{\mathrm{dc}}$ & Shunt dc side resistance \\
\hline $\mathrm{x}_{\mathrm{t} 1}$ & reactance of transformer of SMIB system \\
\hline$r_{e}$ & resistance of the double circuit line \\
\hline $\mathrm{x}_{\mathrm{e}}$ & reactance of the double circuit transmission line \\
\hline $\mathrm{P}_{\text {ref }}$ & reference real power \\
\hline$Q_{\text {ref }}$ & reference reactive power \\
\hline
\end{tabular}

\section{CONCLUSION}

The mathematical model for Unified Power Flow Controller (UPFC) has been developed and the MATLAB experimental results proved the supremacy of the Feed-Back Linearization Controller (FBLC) over the ordinary Proportional Integral (PI) Controller. For all type of disturbances created in the Single Machine Infinite Bus (SMIB) system, the Feed-Back Linearization Controller (FBLC) equipped with Power System Stabilizers (PSS) damped the electromechanical oscillations faster than the Proportional Integral (PI) controller equipped with Power System Stabilizers (PSS).

\section{APPENDIX \\ POWER SYSTEM, AVR and PSS data}

$$
\begin{aligned}
& \text { Base MVA: } 100 \\
& \mathrm{x}_{\mathrm{d}}=\mathbf{1 . 9} \text { p.u., } \mathrm{x}_{\mathrm{q}}=\mathbf{1 . 6} \text { p.u, } \mathrm{x}_{\mathrm{d}}^{\prime}=\mathbf{0 . 1 7} \text { p.u., } \mathrm{T}_{\mathrm{do}}^{\prime}=\mathbf{4 . 3 1 4} \text { sec., } \\
& \mathrm{M}=0.03 \text { p.u., } \mathrm{K}_{\mathrm{e}}=50, \mathrm{~T}_{\mathrm{e}}=0.1 \mathrm{sec}, \mathrm{E}_{\mathrm{fd}}^{\max }=6 \text { p.u., } \\
& \mathrm{E}_{\mathrm{fd}}^{\min }=-6 \text { p.u., } \mathrm{K}_{\mathrm{pw}}=5, \mathrm{~K}_{\mathrm{iw}}=12, \mathrm{D}=0 . \mathrm{u}_{\mathrm{pss}}^{\mathrm{max}}=0.01 \text { p.u., } \\
& \mathrm{u}_{\mathrm{pss}}^{\min }=-0.01 \text { p.u. } ; \mathrm{x}_{\mathrm{t} 1}=0.2 \text { p.u., } \mathrm{x}_{\mathrm{t} 2}=\mathrm{x}_{\mathrm{e}}=0.2 \text { p.u., } \mathrm{r}_{\mathrm{e}}=0.0 \text { p.u., } \omega_{0} \\
& =100 \Pi \mathrm{rad} / \mathrm{sec}
\end{aligned}
$$

$U P F C$

$$
\begin{aligned}
& \mathrm{R}_{\mathrm{p}}=0.04 \text { p.u.; } \mathrm{x}_{\mathrm{p}}=0.1 \text { p.u. } \\
& \mathrm{R}_{\mathrm{dc}}=150 \Omega ; \mathrm{C}=5000 \mu \mathrm{F}
\end{aligned}
$$

GAIN FOR FBLC

$$
\begin{aligned}
& \mathrm{K}_{11}=20 ; \mathrm{K}_{12}=100 ; \mathrm{K}_{21}=350 ; \\
& \mathrm{K}_{22}=35000 ; \mathrm{K}_{23}=1000000 ;
\end{aligned}
$$

\section{REFERENCES}

[1] P. M. Anderson and A. A. Fouad, "Power System Control and Stability". IEEE Press, 1994.

[2] R. Marino, "An example of a nonlinear regulator",IEEE Transactions on Automatic Control, Vol.AC-29, No. 3, pp. 276279, 1984.

[3] J.W. Chapman, M.D. Ilic, C.A. King, L. Eng and H. Kaufman, "Stabilizing a multimachine power system via decentralized feedback linearizing excitation control", IEEE Transactions PowerSystems, Vol. 8, No. 3, 1993.

[4] W. Mielczarski and A.M. Zajaczkowski, "Multivariable nonlinear controller for a synchronous generator", Optimal ControlApplications and Methods, Vol. 15, pp. 49-65, 1994.

[5] O. Akhrif, F.A. Okou, L.A. Dessaint and R.Champagne, "Application of a multivariable feedback linearization scheme for rotor angle stability and voltage regulation of power systems", IEEE Transactions on Power Systems, Vol. 14, No. 2, pp. 620628, 1999.

[6] H. Sira-Ramirez and M. Ilic-Spong," Exact linearization in switched-mode DC to DC power converters", International Journal of Control, Vol.50, No. 2, pp. 511-524, 1989.

[7] D.I. Kim, I.J. Ha and M.S. Ko, "Control of induction motor via feedback linearization with input-output decoupling", International Journal of Control, Vol. 51, No. 4, pp. 863-886, 1990. 
[8] Y.L. Tan and Y. Wang, "Design of series and shunt FACTS controller using adaptive nonlinear coordinated design techniques", IEEE Transactions on Power Systems, Vol. 12, No. 3, pp. 1374-1379, 1997.

[9] L. Gyugyi, Dynamic compensation of AC transmission lines by solid-state synchronous voltage sources, IEEE Transactions on Power Delivery, Vol. 9, pp. 904-911, 1994.

[10] R. Mihaliæ, P. .unko, I. Papiæ and D. Povh, "Improvement of transient stability by insertion of FACTS devices", IEEE/NTUA Athens Power Tech. Conference Proc., pp. 521-525, 1993.

[11] B.M. Han, G.G. Karady, J.K. Park and S.I. Moon, "Interaction analysis model for transmission static compensator with EMTP", IEEE Transactions on Power Delivery, Vol. 13, No. 4, pp. 1297-1302, 1998.

[12] P.W. Lehn and M.R. Irvani, "Experimental evaluation of STATCOM closed loop dynamics, IEEE Transactions on Power Delivery", Vol. 13,No. 4, pp. 1378-1384, 1998.

[13] S. Mori, K. Matsuno, M. Takeda and M. Seto, "Development of a large static VAR generator using self-communicated inverters for improving power system stability", IEEE Transactions on Power Systems, Vol. 8, No. 1, pp. 371-378, 1993.
[14] Wang P., Jenkins N. and Bollen M.H.J., "Experimental Investigation of voltage sag mitigation by an Advanced Static VAR Compensator", IEEE Trans. Power delivery, Vol. 13, No.4,pp.1461-1467.

[15] Yang Z., Shen C, Zhang L. and Crow M.L., "Integration of a STATCOM and Battery Energy Storage", IEEE Trans. on Power System, Vol. 16, No. 2, pp. 254-260,2001.

[16] Chun L., Qirong J. and JianxinX.,'Investigation of Voltage Regulation Stability of Static Synchronous Compensator in power system", IEEE Power Engineering Society, Proceedings of the Winter Meeting, Vol. 4, pp. 2642-2647,2000.

[17] Padiyar K.R. and Kulkurni A.M., "Control design and simulation of a unified power flow controller", IEEE Transactions on Power Delivery, Vol. 13, No. 4, pp. 1348 - 1354.

[18]Saravanailango.G,Nagamani.C, "A non-linear control technique forUPFC based on linearisation," International journal of ElectricPower Components and Systems(Taylor \& Francis), Vol 36;432-447,2008 